\title{
Development lean assessment indicator: A case study
}

\author{
Iffad Rakhmanhuda ${ }^{1, *}$, Putu Dana Karningsih ${ }^{1}$ \\ ${ }^{1}$ Department of Industrial Engineering, Institut Teknologi Sepuluh Nopember, 60111 Surabaya, \\ Indonesia
}

\begin{abstract}
The manufacturing industry is always faced with global challenges such as cost effectiveness, lead time, quality, and safety. Lean as a concept of continuous improvement can be a solution in solving the challenge. PT. Compotec International is one of the companies faced with the problem. Basically, the company has implemented lean concept in its production process, but the lack of understanding and commitment of the company in its implementation still leads to the emergence of waste in the production process. Therefore a comprehensive measurement is needed to assess company performance from several dimensions such as time effectiveness, quality, process, cost, human resources, delivery, customer, and inventory. In the previous lean assessment tools research, safety issues that became the basis of production considerations before making improvements have not been taken yet into account. Therefore it is necessary to integrate waste based indicators related to poor safety. Measurements are done qualitatively and quantitatively using aggregate scoring and fuzzy approaches. From the measurement result and then weighted with Brown-Gibson method to get the value of leanness. then the results of these calculations are combined to be visualized in the form of lean radar chart. In this research, it is hoped that the development of new lean assessment can measure lean performance more comprehensively.
\end{abstract}

\section{Introduction}

Lean assessment is the first step in the implementation of lean manufacturing. According to Feld (2001), there are four stages in the application of lean manufacturing, namely lean manufacturing assessment, current state gap, future state design, and implementation. The objective of the lean assessment is to define leannes's current level of lean implementation by companies or organizations (Almomani, Abdelhadi and Mumani, 2014). Leannes creates a sustainable competitive advantage (Womack, J. P., \& Jones, 1996). However, a lack of clear understanding of lean's performance and its measurement is the cause of the implementation failure of lean itself, making it impossible to implement lean without measuring its performance (Behrouzi and Wong, 2011).

According to Pakdil and Leonard (2014), the use of a single approach to the lean assessment process allows for bias. Pakdil and Leonard (2014) developed a lean assessment

*corresponding author: iffad10@gmail.com 
model using two approaches, namely quantitative assessment and qualitative assessment. Quantitative assessment can measure the application of lean in accordance with the results and objectives that have been implemented, while the qualitative assessment can reflect the perceptions of stakeholders or in the context of companies that can generate different perceptions of assessment. Both lean assessment tools (LAT) provide an overall picture of the company's leannes performance.

Improving safety in the workplace has always been a topic discussed during continuous improvement. Statistics show that an accident incident occurs when a person or an individual does something out of the ordinary, in an unorganized place, or when the individual is required to perform a difficult, risky job without sufficient tool support. So that the work environment should be strived for as safe as possible, and how safety should not be sacrificed in the name of productivity.

\section{Literatur Review}

\subsection{Lean Assesment Tool (LAT)}

Some of the key pillars of lean assessment are size and can align with company strategy, then allow for performance control and evaluation (Taylor, Pakdil and Leonard, 2014). In some ways it is also able to help identify space to make improvements and be realistic on the application. Assessment becomes important in determining the initial step of performance measurement so that further does not lead to incorrect improvement policy. Implementation of lean assessment is also dynamic in accordance with the needs and availability required in case studies and applications.

\subsection{Fuzzy Logic}

Fuzzy logic is an approach method used to optimize uncertainty by using fuzzy numbers or fuzzy sets (Behrouzi and Wong, 2011) in their research to develop lean dynamic evaluation models using fuzzy methodology.

\subsection{Lean Radar Chart}

Lean radar chart is a graph that can describe or visualize the performance or results of calculations from the assessment that has been carried out.. The company management can use the lean radar chart to see the internal effort of the company to be compared with the reference performance (Taylor, Pakdil and Leonard, 2014).

\section{Development of Lean Assesment Indicator}

This research begins with a reference search related theories that can assist researchers in deepening the problem and determine the direction of correct improvement. The purpose of this study is the development and modification of the framework based on previous studies to identify the critical dimensions and waste of the lean assessment results that have been developed, to know the root cause of problems to the performance of lean and waste critical implementation, and to recommend improvement on the production process in the company's production line that showed at Table 1. 
Table 1. Quantitative and qualitative assessment studies.

\begin{tabular}{|c|c|c|c|c|c|c|c|c|c|c|c|c|c|c|c|c|c|c|c|}
\hline & 혈 & 范 & 跑 & 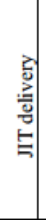 & 㝴 & 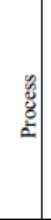 & 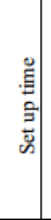 & 㷰 & 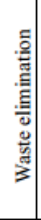 & 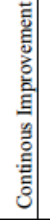 & $\frac{\mathrm{g}}{3}$ & 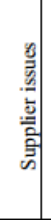 & 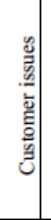 & 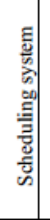 & $\begin{array}{l}\text { : } \\
\vdots \\
\vdots \\
\vdots \\
\vdots \\
0 \\
0\end{array}$ & 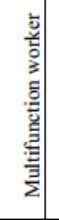 & 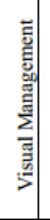 & 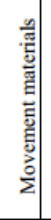 & 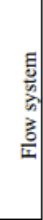 \\
\hline Wan and Chen (2008) & & $\checkmark$ & $\checkmark$ & & & & & & & & & & & & & & & & \\
\hline Maskell (2000) & & $v$ & & & & & & & & & & & & & & & & & \\
\hline Shields (2006) & & & & & $v$ & & & & & & & & & & & & & & \\
\hline Almomani (2014) & $\checkmark$ & & $\checkmark$ & & $v$ & $\checkmark$ & & & & & & & & & & & & & \\
\hline Sanjay Bhasin (2011) & $\checkmark$ & & & $\checkmark$ & & $\checkmark$ & & $\checkmark$ & & $\checkmark$ & & & & & & & $\checkmark$ & & \\
\hline Behrouzi and Wong (2011) & $\checkmark$ & $\checkmark$ & $\checkmark$ & $\checkmark$ & & & & & & & & & & & & & & & \\
\hline Goodson (2002) & $\checkmark$ & & & $v$ & $v$ & & & $\checkmark$ & & & & & $\checkmark$ & & & $v$ & & $\checkmark$ & \\
\hline Shah and Ward (2007) & & & & $v$ & & $\checkmark$ & $v$ & & & & & $v$ & $\sqrt{ }$ & & & $v$ & & & $v$ \\
\hline Pettersen (2009) & & & & & & & & & & & & $\checkmark$ & & $v$ & & & & & \\
\hline Singh (2010) & & & & & & & & & & & & $v$ & $\checkmark$ & & & & & & \\
\hline Isabela Nahmens (2009) & & & & & & & & $\checkmark$ & & & & & & & & & & & \\
\hline Pakdil and Leonard (2014) & $\checkmark$ & $\checkmark$ & $v$ & 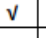 & $v$ & $\checkmark$ & $\checkmark$ & & $\mathrm{v}$ & $\checkmark$ & & $v$ & $\checkmark$ & $\checkmark$ & $v$ & & & $\checkmark$ & $v$ \\
\hline Development LAT (2018) & $\checkmark$ & $\checkmark$ & $\checkmark$ & $\checkmark$ & $v$ & $\checkmark$ & $\checkmark$ & $\checkmark$ & $\checkmark$ & $\checkmark$ & & $\checkmark$ & $\checkmark$ & $\checkmark$ & $\checkmark$ & & & $\checkmark$ & $\checkmark$ \\
\hline
\end{tabular}

\subsection{Integrating Lean Assessment Indicator}

In the quantitative lean assessment indicator shown in Table 2 then the calculation phase of leannes value is done to determine the level of lean implementation in the company's production line. At this stage of collection is collected data to obtain the data needed to carry out research. The data collected at this stage is the company's performance data. Data taken at this stage can be primary data and secondary data. Primary data is data taken directly from the part of the object observation with discussion and interviews to the company. Secondary data is data obtained from recaps company report. 
Table 2. Dimension of Quantitative Indicator

\begin{tabular}{|c|c|}
\hline Dimension & Indicator of measurement \\
\hline \multirow{4}{*}{ Time Effectiveness } & Setup times: Time spent in setups / total productives time \\
\hline & Ratio takt time / cycle time \\
\hline & $\begin{array}{l}\text { Machine downtime : Hours machine lost due to malfunction / } \\
\text { Total machines hour scheduled (percentage) }\end{array}$ \\
\hline & Total time of emergency repairs / total maintenance \\
\hline \multirow{3}{*}{ Quality } & Defect rate \\
\hline & Rework $\%$ of the units that need to be sent to rework \\
\hline & Scrap $\%$ of the products that need to be scrapped \\
\hline \multirow{2}{*}{ Process } & Overall Equipment Effectiveness (OEE) \\
\hline & Capacity utlization rate (idle capacity / total capacity) \\
\hline \multirow{5}{*}{ Human resources } & Absentecism rate \\
\hline & Total of suggestions / total employees \\
\hline & Total of employees working in teams / total employees \\
\hline & Total of hierarchical levels \\
\hline & Total indirect employees / total direct employees \\
\hline \multirow{3}{*}{ Delivery } & $\begin{array}{l}\text { Order lead time : Average time from the placement of an order } \\
\text { (by a customer) to its delivery }\end{array}$ \\
\hline & Ratio total delivery late per year / total delivery per year \\
\hline & Ratio order processing time / total orders \\
\hline \multirow{3}{*}{ Customer } & Customer complaint rate \\
\hline & Customer retention rate \\
\hline & Total products returned by customer / total sales \\
\hline \multirow{2}{*}{ Inventory } & Raw material inventory / total inventory \\
\hline & Finished goods inventory / total inventory \\
\hline \multirow{4}{*}{ Safety } & Incident rate \\
\hline & Lost time case rate \\
\hline & Dart rate \\
\hline & Severity rate \\
\hline
\end{tabular}

\subsection{Calculation}

Calculation is done by using secondary data from indicators that have been modified and quantitative lean assessment done using fuzzy approach, while the qualitative lean assessment is done by using aggregrate scoring approach in Lean Assessment combined. The results of quantitative lean assessment and qualitative lean assessment will be weighted by using Brown-Gibson method to get the value of leannes every dimension. The Table 3 show the result from qualitative assessment and the Table 4 show the result from quantitative assessment. 
Table 3. Qualitative Leannes Score

\begin{tabular}{|c|c|c|c|r|}
\hline Dimension & $\begin{array}{c}\text { Agregat } \\
\text { Scores }\end{array}$ & $\begin{array}{c}\text { Total } \\
\text { Question }\end{array}$ & $\begin{array}{c}\text { Maximum } \\
\text { Total scores }\end{array}$ & Leannes \\
\hline Quality & 44 & 11 & 55 & 0.800 \\
\hline Customer & 9 & 2 & 10 & 0.900 \\
\hline Process & 54 & 14 & 70 & 0.771 \\
\hline $\begin{array}{c}\text { Human } \\
\text { Resources }\end{array}$ & 37 & 8 & 40 & 0.925 \\
\hline Delivery & 52 & 14 & 75 & 0.693 \\
\hline
\end{tabular}

Table 4. Quantitative Leannes Score

\begin{tabular}{|c|c|}
\hline Dimension & Quantitative Scores \\
\hline Quality & 0.998 \\
\hline Customer & 0.865 \\
\hline Process & 0.933 \\
\hline Human Resources & 0.556 \\
\hline Delivery & 0.719 \\
\hline Safety & 0.536 \\
\hline
\end{tabular}

then the results of these calculations are combined to be visualized in the form of lean radar charts as in Figure 1.

\section{Lean Assessment Radar Chart}

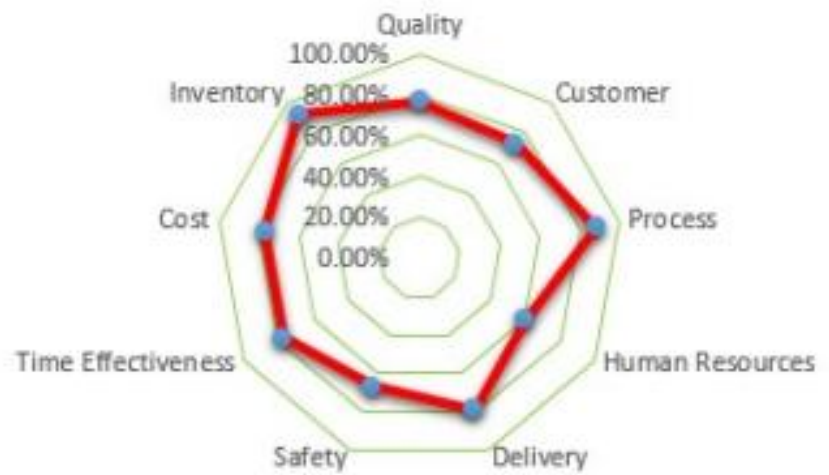

Fig. 1. Lean Radar Chart

\section{Conclusions}

In this study it can be concluded that the qualitative and quantitative measurements on the determination of indicators determine how much accuracy in doing assessment on each dimension. Then from the results of the assessment can be found the value of leannes each 
dimension which can then be identified critical waste so that can be searched the root cause of the problem and continue on the recommendation of correct improvement.

\section{References}

1. Feld, W. M., Lean Manufacturing: Tools, Techniques, and How to Use Them., Alexandria VA: St. Lucie Press,(2001)

2. Almomani, M. A., Abdelhadi, A., Mumani, A., Momani, A. dan Aladeemy, M., A. International Journal of Advanced Manufacturing Technology, 72(1-4), (2014)

3. Womack, J. P., \& Jones, D. T.,. Review Literature And Arts Of The Americas, (1996)

4. Behrouzi, F., and K. Y. Wong., Procedia Computer Science, 3 (388- 395),(2011)

5. Pakdil, F. dan Leonard, K. M., International Journal of Production Research, 52(15), hal. 4587-4607.,(2014)

6. Gaspersz, V., Lean Six Sigma for Manufacturing and Service Industries, 3(2021),(2007) 